\title{
Increasing Student Activeness in Online Learning with the Discovery Learning Model and Interactive Media
}

\section{Any Inti Wahyu Setyaningrum}

SD Negeri 2 Karanganyar

anyinti93@gmail.com

\section{Article History}

accepted $14 / 11 / 2020$

approved $21 / 11 / 2020$

published $26 / 11$

\begin{abstract}
The purpose of this study was to increase student activeness in online learning with discovery learning models and interactive media for grade 4 students at SD Negeri 2 Karanganyar. The subjects were grade 4 SD Negeri 2 Karanganyar, totaling 9 students. The CAR design uses interactive media to increase student activeness in thematic subjects for grade 4 SD Negeri 2 Karanganyar students. Data collection techniques using observation and tests. The data analysis used descriptive quantitative and qualitative statistics. The results showed an increase in student activeness, this can be seen from the observation sheet of the pre-action activities and each cycle, namely in the pre-action it was $22.2 \%$, in cycle I it was $55.6 \%$, while in cycle II it was $88.9 \%$. This was accompanied by an increase in the average student learning outcomes from pre-action by 54.4, cycle I was 63.9, while in cycle II was 81.1. Thus it can be concluded that the use of interactive media can increase student activity in the Thematic learning of grade 4 elementary school students.
\end{abstract}

Keywords: Interactive media, discovery learning, activeness

\begin{abstract}
Abstrak
Tujuan penelitian ini untuk meningkatkan keaktifan siswa pada pembelajaran daring dengan model discovery learning dan media interaktif siswa kelas 4 SD Negeri 2 Karanganyar. Subjeknya adalah siswa kelas 4 SD Negeri 2 Karanganyar yang berjumlah 9 siswa. Desain PTK menggunakan penggunaan media interaktif untuk meningkatkan keaktifan siswa pada mata pelajaran Tematik bagi siswa kelas 4 SD Negeri 2 Karanganyar. Teknik pengumpulan data menggunakan observasi dan tes. Analisis data yang digunakan statistik deskriptif kuantitatif dan kualitatif.

Hasil penelitian menunjukkan adanya peningkatan keaktifan siswa, hal ini dapat dilihat dari lembar observasi dari kegiatan pra tindakan dan setiap siklus, yaitu pada pra tindakan sebesar $22,2 \%$, pada siklus I sebesar $55,6 \%$, sedangkan pada siklus II sebesar $88,9 \%$. Hal tersebut diiringi dengan peningkatan rata-rata hasil belajar siswa dari pra tidakan sebesar 54,4 , siklus I sebesar 63,9, sedangkan pada siklus II sebesar 81,1. Dengan demikian dapat disimpulkan bahwa penggunaan media interaktif dapat meningkatkan keaktifan siswa pada pembelajaran Tematik siswa kelas 4 Sekolah Dasar.
\end{abstract}

Kata kunci: Media interaktif, discovery learning, keaktifan

Social, Humanities, and Education Studies (SHEs): Conference Series https://jurnal.uns.ac.id/shes

p-ISSN 2620-9284

e-ISSN 2620-9292 


\section{PENDAHULUAN}

Menurut Dabbagh dan Ritland (2005), Pembelajaran online adalah sistem belajar yang terbuka dan tersebar dengan menggunakan perangkat pedagogi (alat bantu pendidikan), yang dimungkinkan melalui internet dan teknologi berbasis jaringan untuk memfasilitasi pembentukan proses belajar dan pengetahuan melalui aksi dan nteraksi yang berarti.

Pada masa pandemic covid 19 seperti sekarang pembelajaran online merupakan solusi yang dapat dipilih agar kegiatan belajar mengajar tetap berjalan. Pada pembelajaran online para siswa dan guru dapat bertemu secara virtual.

Dalam pembelajaran online setiap siswa pasti menemui hambatan atau kesulitan, baik yang timbul dari dalam diri siswa ( faktor internal ) maupun dari lingkungan sekitar ( faktor eksternal ). Faktor-faktor yang berpengaruh dalam pembelajaran online tersebut perlu diketahui oleh guru sebagai tenaga pendidik agar dapat dicari dan ditemukan hal-hal yang dapat dijadikan sebagai jalan keluar dari hambatan tersebut.

Pembelajaran online yang menggunakan alat bantu berupa handphone ataupun laptop yang dilaksanakan di SDN 2 Karanganyar Kecamatan Todanan Kabupaten Blora, berdampak pada penurunan prestasi belajar siswa. Sedikit siswa yang dapat menyerap materi yang disampaikan guru melalui pembelajaran online. Penyampaian materi menggunakn metode ceramah dan terbatasnya media atau alat peraga merupakan salah satu penyebab. Sehingga pembelajaran lebih bersifat searah dan membosankan. Oleh karenanya, tidak mengherankan apabila rata-rata pelajaran tematik pada siswa kelas IV Tahun Pelajaran 2020/2021 tidak memenuhi Kriteria Ketuntasan Minimal (KKM) yaitu 70.

Dari hasil pembelajaran online menunjukan $50 \%$ lebih siswa mengalami kesulitan dalam mengikuti pembelajaran. Penguasaan materi pengenalan konsep waktu pada siswa kelas IV semester I tahun 2020/2021 masih jauh dari harapan. Hal tersebut dapat diamati saat siswa tidak aktif dalam pembelajaran. Masih banyak siswa yang diam dan tidak menjawab saat ditanya. Sehingga dari 9 siswa baru 2 siswa atau 22,2\% yang mencapai terget ketuntasan belajar, sedangkan 7 atau $77,8 \%$ siswa belum mencapai hasil yang memuaskan. Dengan keadaan seperti itu, jika dibiarkan tanpa adanya tindakan untuk memperbaiki KBM maka tujuan pembelajaran tidak akan tercapai.

Untuk pelajaran tematik pada siswa kelas IV guru akan menggunakan media interaktif dan model discovery learning. Pembelajaran online dengan menggunkan media interaktif dan model discovery learning tidak akan membuat siswa merasa bosan.

Menurut Ruseffendi (2006:329), Model pembelajaran discovery learning merupakan model yang mengelola pembelajaran yang bisa membuat siswa mendapatkan ilmu pengetahuan secara mandiri dan belum diketahui oleh dirinya secara aktif.

Media pembelajaran merupakan segala sesuatu yang dapat digunakan untuk menyalurkan pesan dan dapat merangsang pikiran, perasaan, perhatian dan kemauan siswa sehingga dapat mendorong terjadinya proses belajar pada diri siswa.

Media pembelajaran interaktif adalah suatu sistem penyampaian pengajaran yang menyajikan materi video rekaman dengan pengendalian komputer kepada penonton (siswa) yang tidak hanya mendengar dan melihat video dan suara, tetapi juga memberikan respon yang aktif, dan respon itu yang menentukan kecepatan dan sekuensi penyajian Seels \& Glasgow (Arsyad, 1997:36).

Berdasarkan uraian diatas, maka penulis tertarik melaksanakan Penelitian Tindakan Kelas (PTK) dengan judul : Peningkatan Keaktifan Siswa Pada Pembelajaran Online Dengan Model Discovery Learning Dan Media Interaktif Siswa Kelas IV SD Negeri 2 Karanganyar Blora Semester 1 Tahun Pelajaran 2020/2021. 


\section{METODE}

Penelitian ini berlokasi di SDN 2 Karanganyar Kecamatan Todanan Kabupaten Blora. Penelitian dilaksanakan pada pertengahan semester gasal tahun pelajaran 2020/2021 sesuai dengan materi Tematik Tema 5 SubTema 2. Subjek penelitian tindakan kelas ini adalah siswa kelas IV SDN 2 Karanganyar Kecamatan Todanan Kabupaten Blora tahun pelajaran 2020/2021. Sebanyak 9, yang terdiri dari 4 siswa perempuan dan 5 siswa laki-laki.

Penelitian ini adalah penelitian tindakan kelas (Classroom Action Research) dengan menerapkan model pembelajaran Discovery Learning. Penelitian ini dilaksanakan selama dua siklus secara daring menggunakan aplikasi Zoom Meeting dengan dua pertemuan disetiap siklusnya. Siklus I dilaksanakan pada tanggal 17 dan 18 November 2020. Siklus II dilaksanakan pada tanggal 23 dan 24 November 2020. Teknik pengumpulan data yang dilakukan dengan observasi dan tes, baik pre test maupun post test. Observasi meliputi observasi keterlaksanaan model Discovery Learning, sikap peserta didik dan keterampilan. Untuk hasil belajar menggunakan tes melalui Google form.

\section{HASIL DAN PEMBAHASAN}

Berdasarkan hasil pelaksanaan dan observasi pada tindakan siklus I dan siklus II, peneliti dapat menyimpulkan bahwa terjadi peningkatan keaktifan belajar siswa siswa kelas 4 SDN 2 Karanganyar Kecamatan Todanan Kabupaten Blora tahun ajaran 2020/2021. Pada pembelajaran Tematik Kelas 4 Tema 5 Sub Tema 2 antara pra tindakan, tindakan siklus I dan tindakan siklus II. Dengan meningkatnya keaktifan belajar siswa diiringi dengan peningkatan hasil belajar siswa kelas 4 .

Tabel 1. observasi keaktifan siswa dalam pembelajaran dengan model Discovery learning siklus I

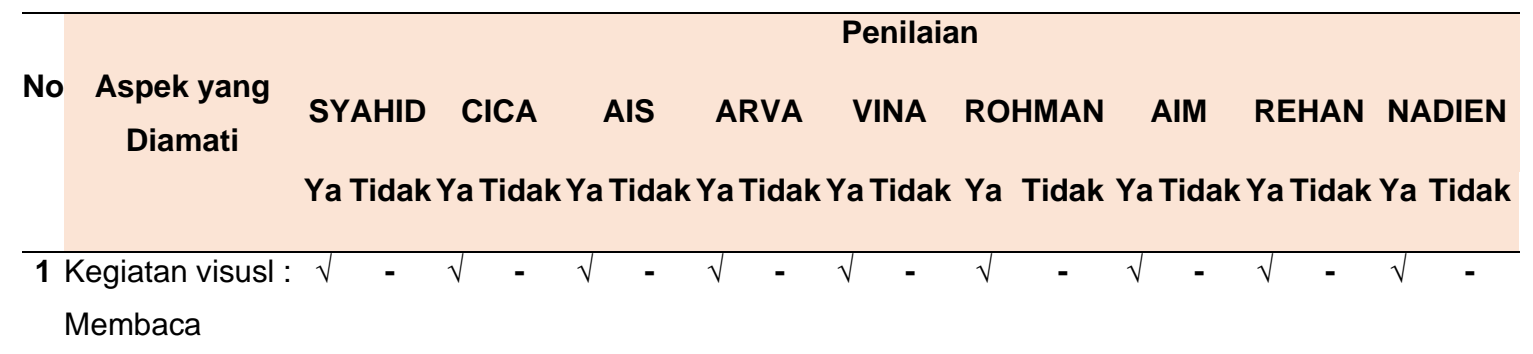


SHEs: Conference Series 3 (3) (2020) 1391- 1399

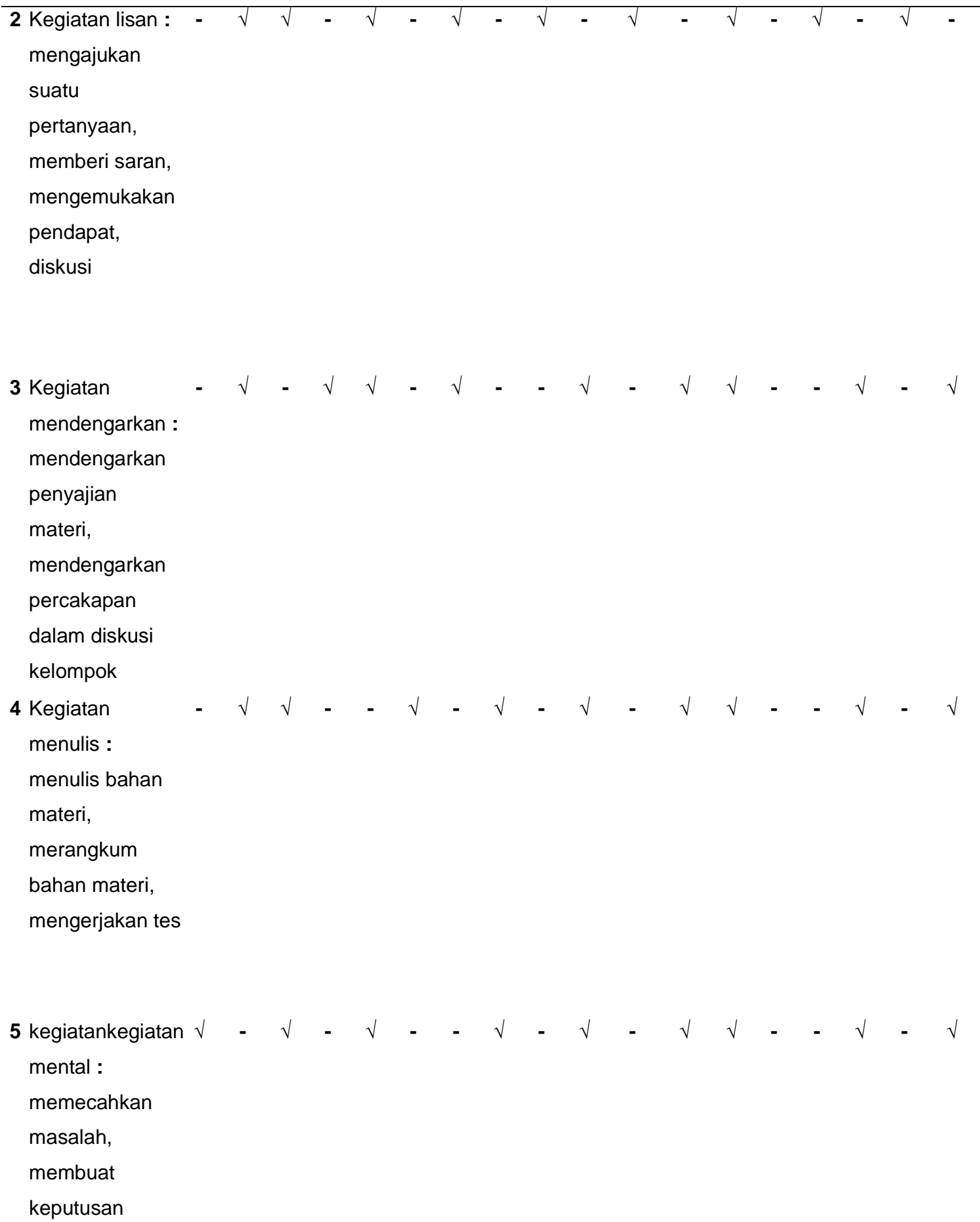


SHEs: Conference Series 3 (3) (2020) 1391- 1399
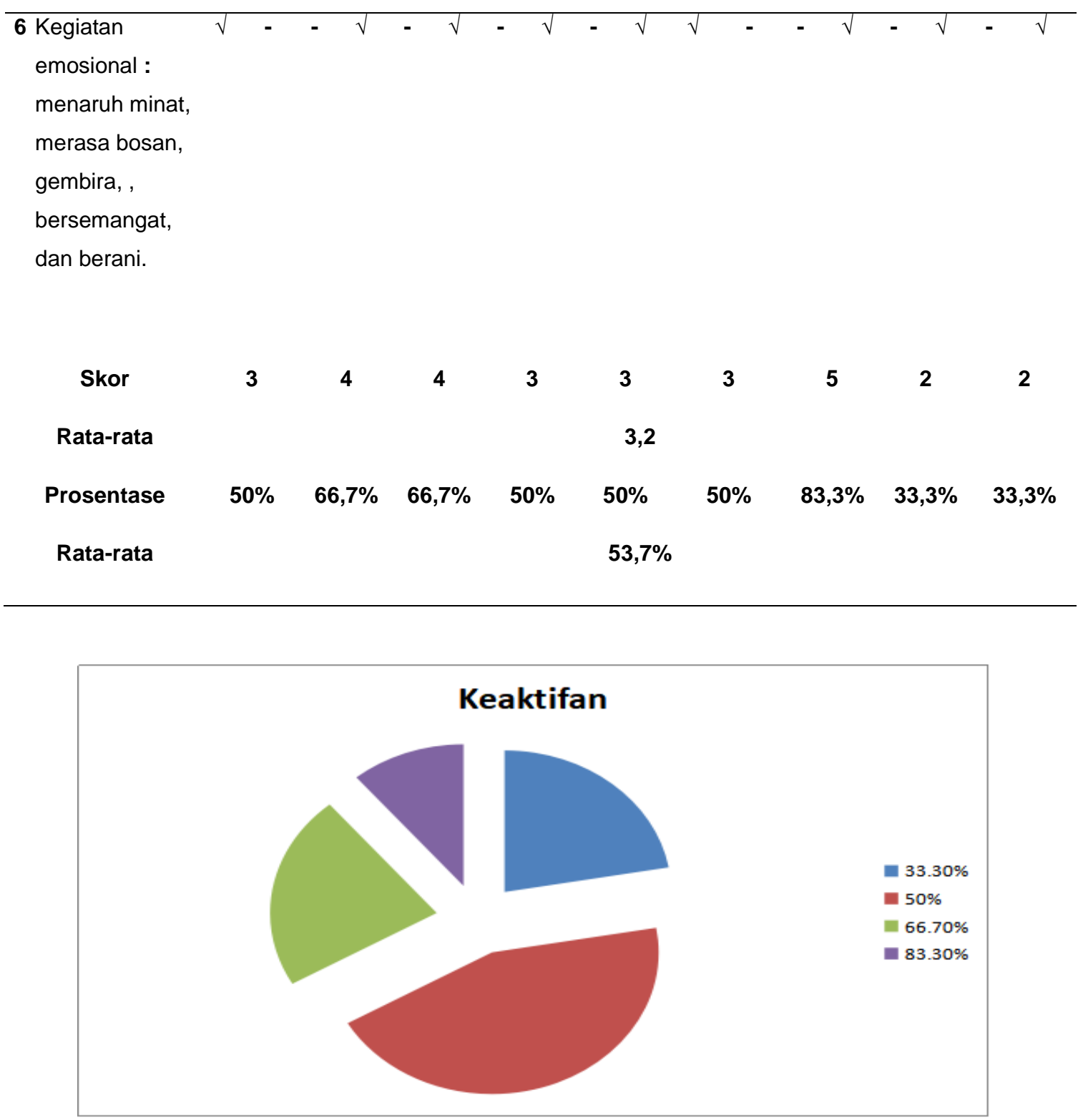

Grafik 1. Diagram keaktifan Siklus I

Hasil observasi keaktifan siswa yang dilaksanakan oleh peneliti dalam mengikuti pembelajaran pada siklus I diperoleh skor 3,2 sedangkan skor maksimumnya adalah 6. Dan hasil prosentasinya adalah $53,7 \%$ yang berarti aktivitas siswa selama mengikuti kegiatan pembelajaran berada dalam kategori kurang.

Tabel 2. observasi keaktifan siswa dalam pembelajaran dengan model Discovery learning siklus II

\begin{tabular}{ccccccc}
\hline & \multicolumn{4}{c}{ Penilaian } \\
No $\begin{array}{c}\text { Aspek yang } \\
\text { Diamati }\end{array}$ & SYAHID & CICA AIS ARVA VINA ROHMAN AIM REHAN NADIEN \\
& Ya Tidak Ya Tidak Ya Tidak Ya Tidak Ya Tidak Ya Tidak YaTidak YaTidak YaTidak \\
\hline
\end{tabular}


SHEs: Conference Series 3 (3) (2020) 1391- 1399

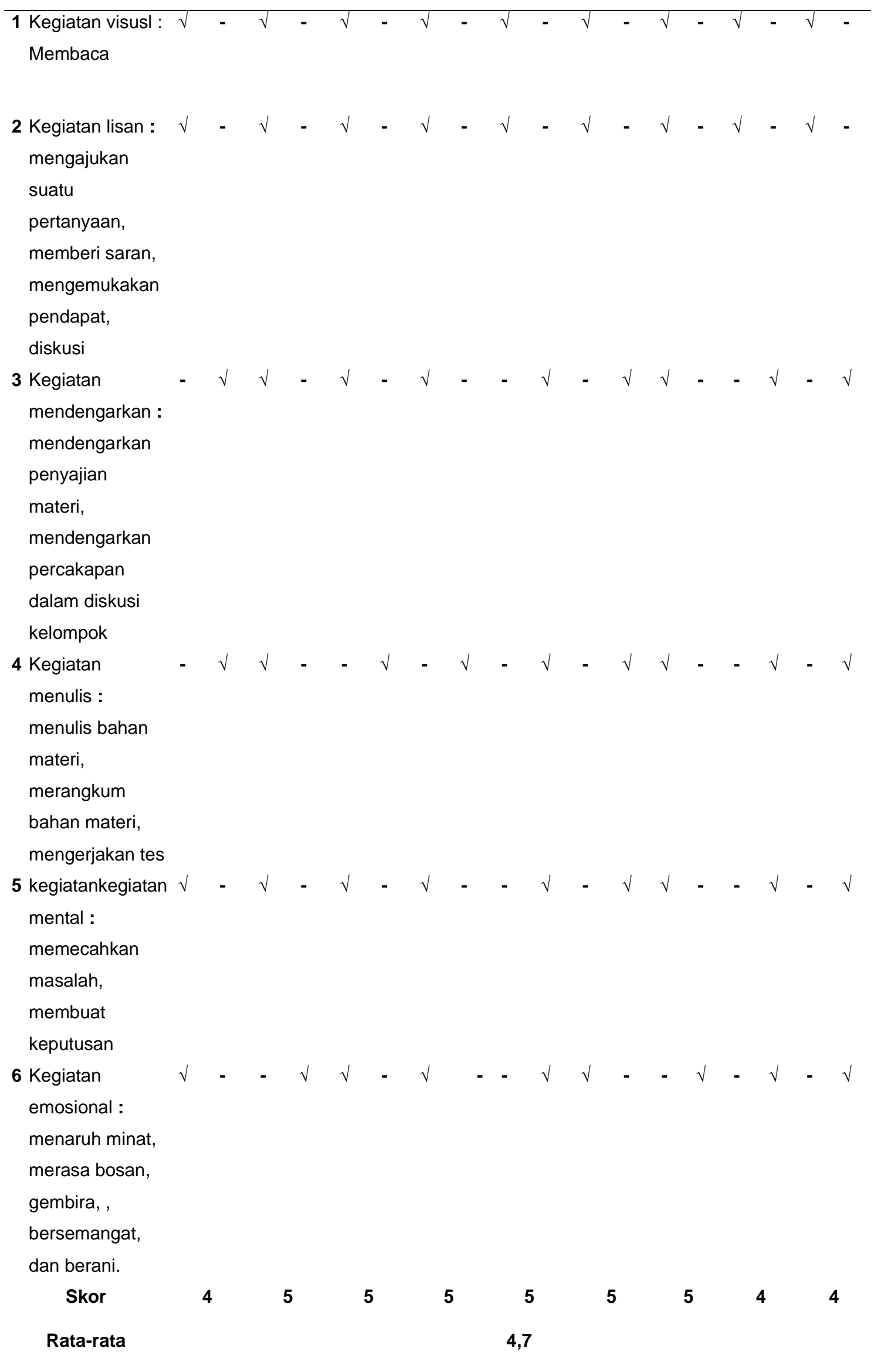




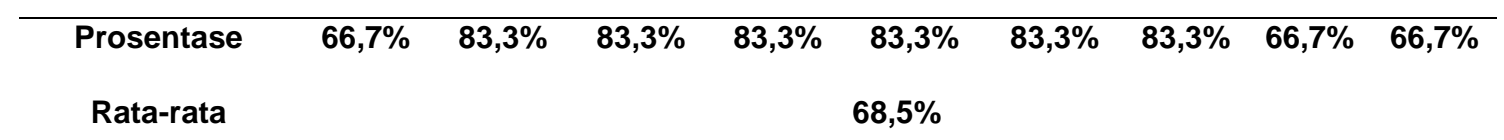

Keaktifan

Grafik 2. Diagram keaktifan Siklus II

Hasil observasi keaktifan siswa yang dilaksanakan oleh peneliti dalam mengikuti pembelajaran pada siklus II diperoleh skor 4,7 sedangkan skor maksimumnya adalah 6 . Dan hasil prosentasinya adalah $68,5 \%$ yang berarti aktivitas siswa selama mengikuti kegiatan pembelajaran berada dalam kategori baik.

Tabel 3. Hasil belajar Prasiklus, siklus I dan II.

\begin{tabular}{|c|c|c|c|c|c|c|c|}
\hline \multirow{2}{*}{ No } & \multirow{2}{*}{ Nama Siswa } & \multicolumn{2}{|c|}{ Prasiklus } & \multicolumn{2}{|c|}{ Siklus I } & \multicolumn{2}{|c|}{ Siklus II } \\
\hline & & $\mathrm{N}$ & Ket & $\mathrm{N}$ & Ket & $\mathrm{N}$ & Ket \\
\hline 1 & $\begin{array}{l}\text { Ahmad Syahid } \\
\text { Hidayatullah }\end{array}$ & 60 & Belum & 60 & Belum & 80 & Tuntas \\
\hline 2 & $\begin{array}{l}\text { Ainun Cica } \\
\text { Mahmudah }\end{array}$ & 60 & Belum & 80 & Tuntas & 100 & Tuntas \\
\hline 3 & $\begin{array}{l}\text { Aisyah Ayu } \\
\text { Mutmainah }\end{array}$ & 50 & Belum & 60 & Belum & 90 & Tuntas \\
\hline 4 & $\begin{array}{c}\text { Alwahabu Arva } \\
\text { Ainun Najib }\end{array}$ & 60 & Belum & 60 & Belum & 80 & Tuntas \\
\hline 5 & Fina Ainul Muna & 50 & Belum & 50 & Belum & 70 & Tuntas \\
\hline 6 & Mohamad Rohman & 40 & Belum & 50 & Belum & 70 & Tuntas \\
\hline
\end{tabular}




\begin{tabular}{cccccccc}
\hline 7 & M. Lukman Hakim & 70 & Tuntas & 90 & Tuntas & 100 & Tuntas \\
8 & $\begin{array}{c}\text { Reyhan Noval } \\
\text { Alfino }\end{array}$ & 40 & Belum & 50 & Belum & 80 & Tuntas \\
& $\begin{array}{c}\text { Nadien Aprilia } \\
\text { Azahra }\end{array}$ & 40 & Belum & 60 & Belum & 60 & Belum \\
\hline
\end{tabular}

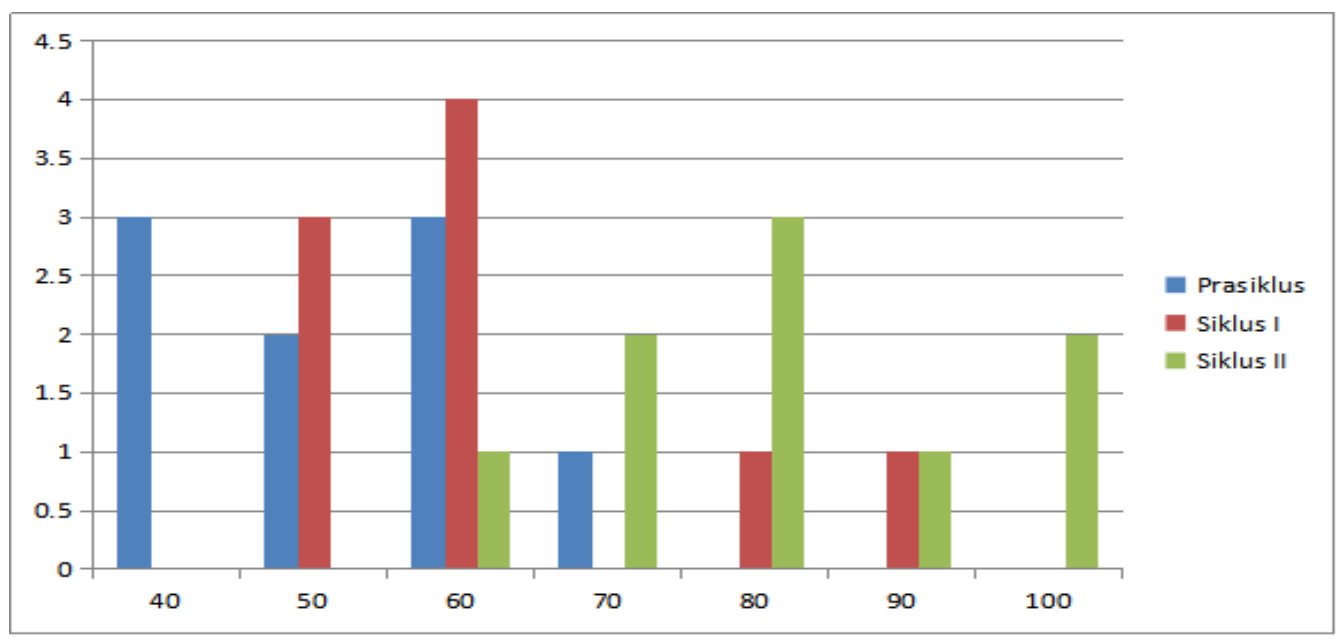

Grafik3. Diagram hasil belajar Prasiklus, siklus I dan II

Prosentase ketuntasan belajar siswa pada prasiklus, siklus I dan siklus II.

\begin{tabular}{lcccccc}
\hline & \multicolumn{2}{c}{ Prasiklus } & \multicolumn{2}{c}{ Siklus I } & \multicolumn{2}{c}{ Siklus II } \\
Kriteria & $\begin{array}{c}\text { Jml } \\
\text { Siswa }\end{array}$ & $\begin{array}{c}\text { Prosen } \\
\text { tase }\end{array}$ & $\begin{array}{c}\text { Jml } \\
\text { Siswa }\end{array}$ & $\begin{array}{c}\text { Prosen } \\
\text { tase }\end{array}$ & $\begin{array}{c}\text { Jml } \\
\text { Siswa }\end{array}$ & $\begin{array}{c}\text { Prosen } \\
\text { Tase }\end{array}$ \\
\hline Tuntas & 1 & $11,11 \%$ & 2 & $22,22 \%$ & 8 & $88,89 \%$ \\
Belum & 8 & $88,89 \%$ & 7 & $77,78 \%$ & 1 & $11,11 \%$ \\
Jumlah & 9 & $100 \%$ & 9 & $100 \%$ & 9 & $100 \%$ \\
\hline
\end{tabular}

Tabel 4. Prosentase ketuntasan belajar siswa pada prasiklus, siklus I dan siklus II

Setelah melihat hasil observasi yang dilakukan peneliti di atas, maka peneliti, menyimpulkan bahwa tindakan kelas yang dilakukan berhasil dengan baik karena dari hasil observasi awal anak yang mengalami ketuntasan belajar hanya 1 orang siswa ( $11,11 \%)$. Setelah dilakukan tindakan siklus I siswa yang berhasil mencapai Ketuntasan dalam belajarnya meningkat menjadi 2 ( $22,22 \%$ ) orang siswa, yang belum berhasil tinggal $7(77,78 \%)$ orang siswa. Selanjutnya pada tindakan siklus II siswa 
yang berhasil mencapai ketuntasan belajarnya meningkat lagi menjadi 8 ( $88,89 \%)$ orang siswa.

\section{SIMPULAN}

Berdasarkan hasil analisis data pada penelitian tindakan kelas tentang penggunaan model pembelajaran Discovery Learning dengan berbantukan media Interaktif pada pembelajaran tematik untuk meningkatkan keaktifan dan hasil belajar siswa kelas IV SDN Karanganyar, Todanan, Blora maka dapat disimpulkan bahwa: (1) Aktivitas guru pada saat pembelajaran terjadi peningkatan dibuktikan dengan perseantase kenaikan pada siklus II. (2) Keaktifan dan hasil belajar siswa mengalami peningkatan. Hal ini ditunjukan dengan antusias siswa selama mengikuti pembelajaran yang ditunjukkan siswa selama proses pembelajaran, kemandirian siswa dalam menjawab pertanyaan-pertanyaan dari guru dan mengerjakan LKPD, kepercayaan diri siswa dalam mengikuti diskusi bersama pasangan dan saat mempresentasikan hasil diskusi melalui rekam video. Berdasarkan penelitian yang telah dilakukan dengan menggunakan model pembelajaran Discovery Learning dengan berbantukan media Interaktif maka beberapa saran yang diajukan adalah sebagai berikut: 1) Guru diharapkan dapat menggunakan model pembelajaran Discovery Learning pada mata pelajaran Tematik lainnya serta serta lebih kreatif dalam menerapkan model pembelajaran. 2) Selajutnya diharapkan dapat menggunakan media pembelajaran yang efektif dan menarik di dalam proses pembelajaran sehingga dapat meningkatkan motivasi dan perhatian siswa selama mengikuti pembelajaran.

\section{DAFTAR PUSTAKA}

Arifin, Zainal. 2011. Penelitian Pendidikan : Metode dan Paradigma Baru. Bandung: PT. Remaja Rosdakarya

Arikunto, Suharsimi. 2006. Penelitian Tindakan Kelas. Jakarta : PT. Bumi aksara Asrori, Mohammad. 2007. Penelitian Tindakan Kelas. Bandung : CV. Wacana prima Basrowi. 2008. Prosedur Penelitian Tindakan Kelas. Bogor : Ghalia Indonesia Dalyono. 2009. Psikologi Pendidikan. Jakarta: Rineka Cipta. 